Maximiliano Loiola Ponte de Souza

(1) http///orcid org/0000-0002-4373-7016

Everton do Carmo Barbosa²

Ohttps://orcid.org/0000-0003-2964-2157

Davi Queiroz de Carvalho Rocha²

(-) https://orcid.org/0000-0003-4032-0626

Fernando José Herkrath 3,4

(1) https://orcid org/0000-0003-4439-0189

\section{Reduction in hospitalizations and emergency psychiatric care due to social distancing measures during the COVID-19 pandemic}

\author{
Redução nas hospitalizações e atendimentos psiquiátricos de emergência \\ devido a medidas de distanciamento social durante a pandemia de COVID-19
}

DOI: $10.1590 / 0047-2085000000307$

\begin{abstract}
Objective: Assess the impact of the lockdown measures on hospitalizations and emergency psychiatric care in a capital of a Brazilian state. Methods: Psychiatric hospitalizations and emergency psychiatric attendances carried out between January 7th and May 28th, 2020, were evaluated, covering the periods before and after lockdown due to COVID-19 pandemic in the city of Fortaleza, capital of the state of Ceará, Brazil. The data in the two periods were described and presented in time series graphs. Attendances were also described according to the severity categories. Comparisons were performed using Mann-Whitney $U$ test and test for proportions. Results: The daily average of hospitalizations and of attendances decreased in the evaluated periods from 16.0 to 10.8 ( $p<0.001$ ) and 67.9 to 35.0 $(p<0.001)$, respectively. This absolute reduction was observed in all categories of severity. No difference was observed in the proportion of severe attendances ( $2.3 \%$ vs. $2.8 \% ; p=0.207)$. The proportion of mild cases decreased from $18.6 \%$ to $10.7 \%(p<0.001)$ and of intermediate severity cases increased from $79.1 \%$ to $86.5 \%$ ( $p<0.001$ ). Conclusion: The findings showed both a decrease in emergency psychiatric attendances and hospitalizations, which can lead to severe impacts in the absence of counterpart mitigation measures by the local mental health system.
\end{abstract}

\section{KEYWORDS}

Psychiatric emergency services, social isolation, COVID-19.

\section{RESUMO}

Objetivo: Avaliar o impacto das medidas de distanciamento social em hospitalizações e atendimentos psiquiátricos de urgência em uma capital de estado brasileiro. Métodos: Foram avaliadas as internações e atendimentos psiquiátricos de urgência realizados entre 7 de janeiro e 28 de maio de 2020, abrangendo os períodos antes e após o lockdown em razão da pandemia de COVID-19 na cidade de Fortaleza, capital do estado do Ceará, Brasil. Os dados nos dois períodos foram descritos e apresentados em gráficos de séries temporais. Os atendimentos também foram descritos de acordo com as categorias de gravidade. As comparações foram realizadas pelo teste $U$ de Mann-Whitney e o teste de hipóteses para proporções. Resultados: A média diária de internações e de atendimentos diminuiu nos períodos avaliados, de 16,0 para 10,8 ( $p<0,001$ ) e de 67,9 para 35,0 ( $p<0,001$ ), respectivamente. Tal redução absoluta foi observada em todas as categorias de gravidade. Não foi observada diferença na proporção de atendimentos graves $(2,3 \%$ vs. 2,8\%; $p=0,207)$. A proporção de casos leves diminuiu de 18,6\% para 10,7\% ( $p<0,001$ ) e a de gravidade intermediária aumentou de 79,1\% para 86,5\% ( $p<0,001)$. Conclusão: Os resultados mostraram uma diminuição nos atendimentos psiquiátricos de urgência e nas hospitalizações, o que pode levar a impactos severos na ausência em contrapartida de medidas de mitigação pelo sistema de saúde mental local.

\section{PALAVRAS-CHAVE}

Serviços de emergência psiquiátrica, isolamento social, COVID-19.

Received in: Aug/14/2020. Approved in: 0ct/26/2020.

1 Fundação Oswaldo Cruz, Escritório Técnico, Eusébio, CE, Brasil.

2 Hospital de Saúde Mental Professor Frota Pinto, Fortaleza, CE, Brasil

3 Fundação Oswaldo Cruz, Instituto Leônidas e Maria Deane, Manaus, AM, Brasil.

4 Universidade do Estado do Amazonas, Escola Superior de Ciências da Saúde, Manaus, AM, Brasil.

Address for correspondence: Maximiliano Loiola Ponte de Souza. Fiocruz Ceará - Fundação Oswaldo Cruz. Rua São José, s/n - 61760-000 - Eusébio, CE, Brasil. E-mail: maxkaelu@hotmail.com 


\section{INTRODUCTION}

With a restricted arsenal of prevention strategies to control the progress of COVID-19 pandemic, governments have prioritized measures that limit social interaction, restricting economic, and the circulation of people, strategies named in the study of lockdown measures. Such measures, although effective ${ }^{1}$, in the absence of mitigation strategies can negatively impact the most vulnerable populations, such as the poorest and the chronically ill, with emphasis on people with mental disorders', who usually demand continued access to health services, even needing emergency care and hospital admissions. The challenge of simultaneously facing the COVID-19 health crisis and protecting the most vulnerable, ensuring access to mental health services for example, is even greater in the context of emerging countries, where resource scarcity is more patent. Thus, the objective of the study was to assess the impact of the lockdown measures on hospitalizations and emergency psychiatric care in a capital of a Brazilian state.

\section{METHODS}

The study was carried out using unidentified administrative data of psychiatric hospitalizations and emergency psychiatric care carried out between January 7th and May 28th, 2020, representing two-time intervals, seventy days before and after March 19th, 2020, date of the beginning of the state decree that determined the intensification of social distancing measures (lockdown) in the city of Fortaleza, capital of the state of Ceará, Brazil.

Fortaleza has an estimated population of 2,669,342 inhabitants ${ }^{3}$. Until July 13th the municipality had officially 38,368 confirmed cases and 3,536 deaths by COVID-194. In June the estimated proportion of the population with antibodies to the new coronavirus in the city of Fortaleza was among the highest in the country $(20.2 \%)^{5}$.

The study was conducted at Professor Frota Pinto Mental Health Hospital, the only public service to attend psychiatric emergencies in the city. To face the COVID-19 health crisis, the service developed a contingency plan, adapting international recommendations to the local context ${ }^{6,7}$. These measures include greater rigor in the criteria for hospitalization, allocation of space for quarantine for newly admitted patients and a separate place for those with mild flu-like syndromes. Screening interviews were also adopted for all patients who arrived for emergency care, what was not performed in the pre-lockdown period. Less complex cases that could be dealt in primary or secondary care were not admitted, being referred to other services. Such conduct aimed to reduce the crowding of people in the psychiatric emergency care sector.
The investigated variables were the number of hospitalizations and daily emergency psychiatric care. The attendances were classified by the psychiatrist according to risk, on a color scale, in a local adaptation of the Manchester scale $^{8}$. For the study, attendance was grouped into three severity categories: severe (red and orange), intermediate (yellow and green) and mild (blue and white). In the postlockdown period, the screened and referred cases were included in the number of attendances and classified as mild.

The data were imported into the Stata SE software, version 15, and then the averages of hospitalizations and emergency psychiatric care in the periods before and after the lockdown were calculated, as well as the respective standard deviations and minimum and maximum values. The attendances were also described according to the severity categories. Furthermore, the daily evolution in the number of hospitalizations and attendances was presented in time series graphs. Mann-Whitney $U$ test was used to compare hospitalizations and attendances between the two periods, and the proportion of attendances by severity group were compared using a hypothesis test for proportions (prtest), including the estimation of 95\% confidence intervals.

\section{RESULTS}

The data showed that 1,118 and 770 hospitalizations were indicated, before and after lockdown, respectively. Before the lockdown, 4,754 attendances were carried out, and afterwards, 3,116. Among the latter, 641 patients were screened and referred to other services. Table 1 summarizes the values of the variables assessed in the study.

The daily average of hospitalizations decreased from 16.0 to 10.8 in the evaluated periods $(p<0.001)$. The average of daily attendances decreased from 67.9 to 35.0 ( $p<0.001$ ). This absolute reduction was observed in all categories of severity, mild $(p<0.001)$, intermediate $(p<0.001)$ and severe $(p<0.01)$. The daily values, as well as the adjusted trends are shown in Figure 1.

In the assessment of the proportion of visits by severity categories, no difference was identified in the proportion of severe attendances (2.3\% versus 2.8\%; $p=0.207$ ). The proportion of mild cases decreased from $18.6 \%$ to $10.7 \%$ ( $p$ $<0.001$ ) and proportion of cases with intermediate severity increased from $79.1 \%$ to $86.5 \%$ ( $p<0.001)$.

\section{DISCUSSION}

Although factors such as social isolation, financial impacts, uncertainty were expected to contribute to an increased demand for emergency psychiatric care after the lockdown?, the results showed that this did not occur. After the 
Table 1. Descriptive analysis of the variables evaluated in the study.

\begin{tabular}{|c|c|c|c|c|}
\hline Variable & Daily average & $\pm \mathrm{SD}$ & Minimum & Maximum \\
\hline \multicolumn{5}{|l|}{ Before lockdown } \\
\hline Hospitalizations & 16.0 & 4.5 & 8 & 27 \\
\hline Attendances & 67.9 & 17.1 & 30 & 150 \\
\hline Mild & 12.6 & 7.1 & 4 & 47 \\
\hline Intermediate & 53.7 & 13.2 & 24 & 101 \\
\hline Severe & 1.6 & 1.5 & 0 & 6 \\
\hline \multicolumn{5}{|l|}{ After lockdown } \\
\hline Hospitalizations & 10.8 & 3.3 & 4 & 21 \\
\hline Attendances & 35.0 & 8.5 & 18 & 59 \\
\hline Mild & 3.7 & 4.3 & 0 & 15 \\
\hline Intermediate & 30.3 & 7.2 & 16 & 49 \\
\hline Severe & 1.0 & 1.1 & 0 & 4 \\
\hline
\end{tabular}
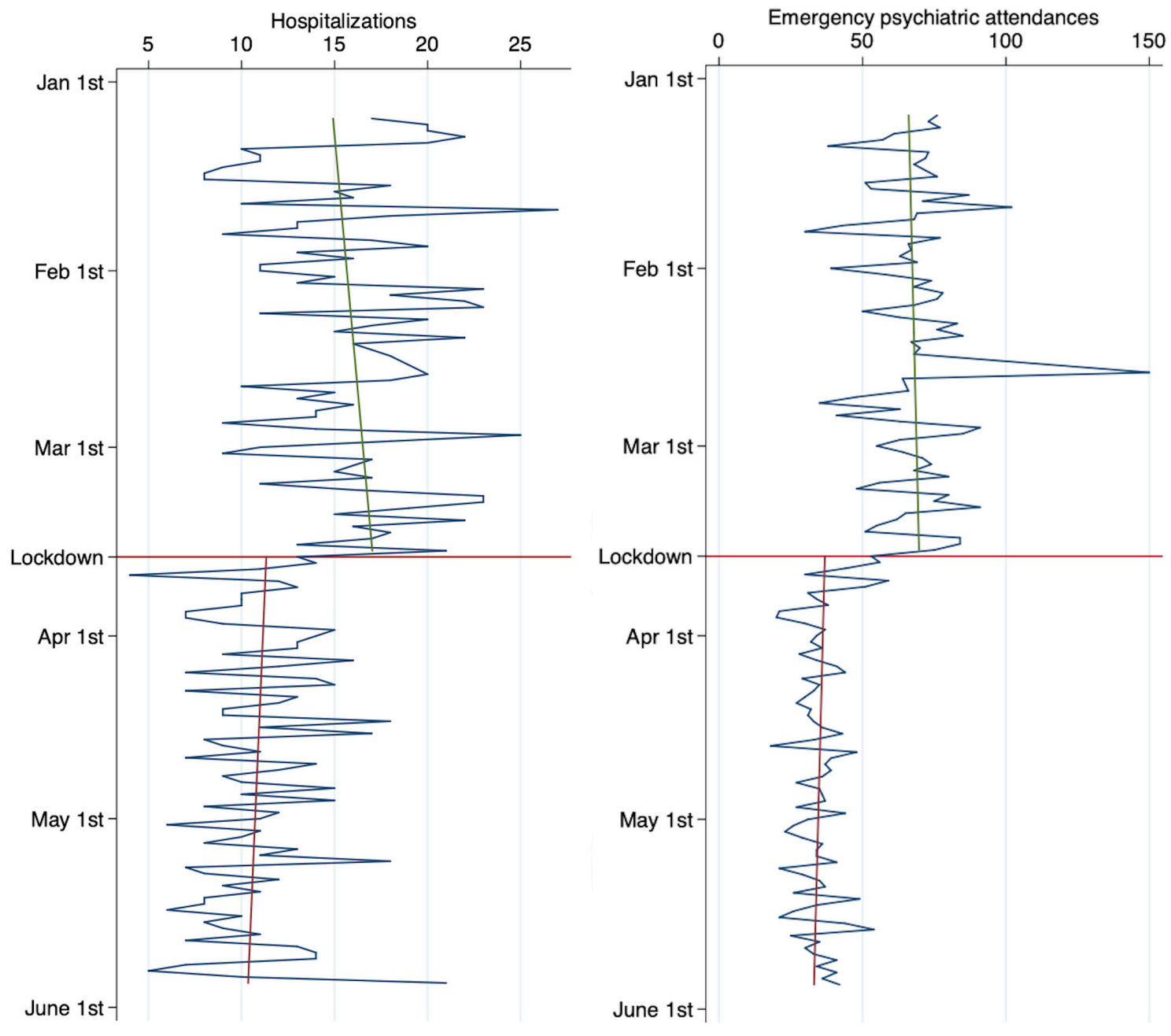

Figure 1. Daily hospitalizations and emergency psychiatric attendances along with adjusted linear trends in the periods before and after the lockdown. 
lockdown, there was a decrease of $48.2 \%$ in the average number of daily attendances to the psychiatric emergency room. A possible explanation for this reduction was the adoption of a screening scheme for patients who arrived for emergency care. During the lockdown period, 631 people sought care, but were referred to other services. However, the findings showed that non-attendance of these patients was not enough to explain the magnitude of the observed reduction.

A reduction in attendance at the psychiatric emergency was also observed in Mannheim, Germany ${ }^{10}$, and New Haven, United States ${ }^{11}$. In these cities, two important motivations for the decrease were pointed out, the general reduction in urban mobility and the fear of getting an infection in the hospital, which would result in a greater selectivity of cases that would seek care in the psychiatric emergency service. Such explanations can be applied to the context evaluated in the study, as there were campaigns for people to stay at home and avoid health services as much as possible. In Fortaleza, the uncritical adoption of these recommendations by the population may have been associated with a decrease in the attendances performed in the cardiological emergency ${ }^{12}$. It is important notice that although there was a reduction in psychiatric care in all categories of severity, there was a greater selectivity in the use of the emergency service, as after the lockdown there was a decrease in the proportion of mild cases, in the absence of change in the proportion of severe cases attended.

The decrease in attendance could also be related to telemedicine strategies instituted during the health crisis that have been able to reduce in-person visits ${ }^{11}$. Such explanation seems less likely for the evaluated context, since there was no locally effective mass adoption of tele-care strategies in the mental health area, and that part of the outpatient care was even reduced in the municipality.

Another important finding was the $32.5 \%$ reduction in psychiatric hospitalizations during the lockdown period. A similar decrease was seen in Lombardy, Italy, which was significantly influenced by the reduction in voluntary hospitalizations ${ }^{13}$. The authors presented two main justifications for this decrease: the aforementioned fear of people becoming infected and the adoption of stricter criteria for hospitalization.

The restriction of hospitalization criteria and the consequent decrease in the hospitalized population is one of the main recommendations for preventing COVID-19 infection in psychiatric hospitals. This strategy is internationally recommended, together with the adoption of others that can mitigate the possible negative effects of this restraint on access to specialized services ${ }^{7}$. In Fortaleza, the recommendation was adopted for professionals to be more judicious when indicating psychiatric hospitalizations, besides having been suspended at the evaluated hospital voluntary hospitalization of patients with problems related to drug addiction, as already stated. It is important to highlight that, similarly to what was observed in Lombardy ${ }^{13}$, the reduction in hospitalizations in Fortaleza may in part be related to the decrease in voluntary hospitalizations. While in Italy this reduction would have resulted from an option for patients or relatives, in Brazil it would have resulted from a restriction of access to a health service, due to the closure of a voluntary hospitalization unit. On the other hand, it is not known whether the local mental health system has effectively implemented counterpart mitigation measures, related to the narrowing of psychiatric hospitalizations in general, or to the suspension of voluntary hospitalizations for drug addiction.

Reduction in emergency psychiatric attendances and hospitalizations have the potential to contribute to the prevention of the spread of COVID-19 infection in general and in the hospital environment, in particular. It is assumed that these reductions are directly or indirectly associated with public policies of macro level (e.g. circulation restriction) and micro level (screening, restriction of hospital admission criteria, closing of units for voluntary admission to drug addicts). However, such necessary restrictive measures do not seem to have been accompanied, on an equal scale, by mitigating counterpoint measures.

This study was able to evidence the impact of actions to face the COVID-19 pandemic in psychiatric care, allowing to think about their specificities in the context of developing countries, where the lack of resources ends up causing restrictive strategies to be implemented in the absence of mitigation, with potentially harmful consequences. Exclusively in the field of mental health, successive deaths from alcohol withdrawal syndrome in India and suicide in Bangladesh can be cited as a consequence of this incomplete adoption of strategies ${ }^{14,15}$.

\section{CONCLUSION}

Thefindings showed both a significant decrease in emergency psychiatric attendances and hospitalizations, which can lead to severe impacts in the absence of counterpart mitigation measures by the local mental health system.

\section{INDIVIDUAL CONTRIBUTIONS}

Maximiliano Loiola Ponte de Souza - Contributed to the study conception and design, data analysis and interpretation, writing and review of the article and approval of the final version to be published. 
Everton do Carmo Barbosa - Contributed to the analysis and interpretation of data, writing and review of the article and approval of the final version to be published.

Davi Queiroz de Carvalho Rocha - Contributed to the analysis and interpretation of data, writing and review of the article and approval of the final version to be published.

Fernando José Herkrath - Contributed to the study conception and design, data analysis and interpretation, writing and review of the article and approval of the final version to be published.

\section{CONFLICT OF INTERESTS}

The authors declare no potential conflict of interests with respect to the research, authorship and/or publication of this article.

\section{REFERENCES}

1. Nussbaumer-Streit B, Mayr V, Dobrescu Al, Chapman A, Persad E, Klerings I, et al. Quarantine alone or in combination with other public health measures to control COVID-19: a rapid review. Cochrane Database Syst Rev. 2020;4:CD013574.

2. Hao F, Tan W, Jiang $L$, Zhang $L$, Zhao X, Zou Y, et al. Do psychiatric patients experience more psychiatric symptoms during COVID-19 pandemic and lockdown? A case-control study with service and research implications for immunopsychiatry. Brain Behav Immun. 2020;87:100-6.

3. Brazilian Institute of Geography and Statistics. Population Estimates: Estimates of resident population for Municipalities and Federation Units. Reference date July 1st, 2019. Available from: https://www.ibge.gov.br//en/statistics/social/population/18448- estimates-of-resident-population-for-municipalities-and-federation-units. html?=\&t=0-que-e. Acessed on: July 3, 2020.

4. Ceará State Government. IntegraSUS. Boletim epidemiológico novo coronavírus (COVID-19). Available from: https://indicadores.integrasus.saude.ce.gov.br/indicadores/ indicadores-coronavirus/coronavirus-ceara. Acessed on: July 14, 2020.

5. EPICOVID19. EPICOVID19-BR divulga novos resultados sobre o coronavírus no Brasil. Available from: https://bit.ly/Epicovid19BRfases1-3. Acessed on: July 3, 2020.

6. Xiang YT, Zhao YJ, Liu ZH, Li XH, Zhao N, Cheung T, et al. The COVID-19 outbreak and psychiatric hospitals in China: managing challenges through mental health service reform. Int J Biol Sci. 2020;16:1741-4.

7. Kuzman MR, Curkovic M, Wasserman D. Principles of mental health care during the COVID-19 pandemic. Eur Psychiatry. 2020;63:e45.

8. Parenti N, Reggiani MLB, lannone P, Percudani D, Dowding D. A Systematic Review on the Validity and Reliability of an Emergency Department Triage Scale, the Manchester Triage System. Int J Nurs Stud. 2014;51:1062-9.

9. Yao H, Chen JH, Xu YF. Patients with mental health disorders in the COVID-19 epidemic. Lancet Psychiatry. 2020;7:e21.

10. Hoyer C, Ebert A, Szabo K, Platten M, Meyer-Lindenberg A, Kranaster L. Decreased utilization of mental health emergency service during the COVID-19 pandemic. Eur Arch Psychiatry Clin Neurosci. 2020:1-3.

11. Goldenberg MN, Parwani V. Psychiatric emergency department volume during Covid-19 pandemic. Am J Emerg Med. 2020:S0735-6757(20)30450-2.

12. Falcão JLAA, Rabelo DRV, Falcao SNRS, Pereira Neto JA, Arnauld FCS, Belém LS, et al. Impact of social isolation during COVID-19 pandemic on arrivals at emergency department and on percutaneous coronary intervention for myocardial infarction at a cardiology hospital. J Transcat Intervent. 2020;28:eA20200009.

13. Clerici M, Durbano F, Spinogatti F, Vita A, Girolamo G, Micciolo R. Psychiatric hospitalization rates in Italy before and during COVID-19: did they change? An analysis of register data. Ir J Psychol Med. 2020;37(4):283-90.

14. Varma RP. Alcohol withdrawal management during the Covid-19 lockdown in Kerala. Indian J Med Ethics. 2020;V:105-6.

15. Bhuiyan AKMI, Sakib N, Pakpour AH, Griffiths MD, Mamun MA. COVID-19-Related Suicides in Bangladesh Due to Lockdown and Economic Factors: Case Study Evidence from Media Reports. Int J Ment Health Addict. 2020:1-6. 